\title{
Occupation and metabolic syndrome: is there correlation? A cross sectional study in different work activity occupations of German firefighters and office workers
}

\author{
Markus Strauß ${ }^{1 *}$, Peter Foshag ${ }^{1}$, Bianca Przybylek¹, Marc Horlitz², Alejandro Lucia ${ }^{3,4}$, Fabian Sanchis-Gomar ${ }^{3}$ \\ and Roman Leischik ${ }^{1}$
}

\begin{abstract}
Background: The treatment and prevention of the metabolic syndrome (MetS) is currently one of the major challenges in medicine. The impact of working conditions on metabolic risk has not been adequately studied. Our objective was to compare the prevalence of MetS and metabolic risk in two extremely different occupational groups: firefighters and office workers.

Methods: A total of 143 male subjects (97 firefighters and 46 office workers) from Germany participated in the study. Anthropometric characteristics, metabolic risk parameters as well as laboratory parameters were collected. MetS was diagnosed according to criteria of the International Diabetes Federation.

Results: Sedentary occupation showed a significant tendency towards obesity. Abdominal waist circumference was significantly greater in office workers than in firefighters [5.08 Cl (1.44-8.71), $\mathrm{p}=0.007$ ]. Concerning metabolic risk factors, abnormal HDL, triglycerides, BMI, blood pressure and waist circumference values were more frequently found in office workers than in firefighters. The MetS was detected in almost $33 \%$ of office workers as compared with only $14 \%$ in firefighters $(p=0.015)$. Regarding MetS in an international comparison, the prevalence of MetS in German office workers was high and in firefighters it was extremely low.
\end{abstract}

Conclusions: Sedentary occupation as an office worker is associated with a high risk of MetS. Both groups need to be made aware of the metabolic risks, and health promoting concepts such as corporate sports activities or education in healthy nutrition need to be implemented to counteract the development of the MetS and cardiovascular risk factors.

Keywords: Office worker, Firefighter, Metabolic syndrome, Metabolic risk factors, Metabolic risk

\section{Background}

The prevalence of the metabolic syndrome (MetS) is steadily rising in the Western world and its prevention and treatment is a major challenge in medicine. It is estimated that in the year 2025, nearly 300 million people

\footnotetext{
*Correspondence: markus.strauss@uni-wh.de

1 Department of Cardiology, Sector preventive medicine, health promotion, Faculty of Health, School of Medicine, University Witten/ Herdecke, Elberfelderstr. 1, 58095 Hagen, Germany

Full list of author information is available at the end of the article
}

worldwide will be diagnosed with diabetes mellitus, a disease that is associated with MetS [1]. In Germany, the prevalence of the MetS is $23 \%$, with an upward trend [2]. Proportionally, the MetS is more common in men than in women [3].

The MetS comprises a constellation of interrelated metabolic disorders, including hypertension, central obesity, dyslipidemia atherosclerosis and hyperglycemia, that are associated with increased risk for cardiovascular disease, leading to increased morbidity and mortality [4-6]. Physical inactivity is also an important determinant for the 
MetS [7]. Although the working definition of the MetS varies among professional societies, all recognised definitions include a measure of obesity and insulin resistance.

The prevalence of the MetS and diabetes can be determinated by environmental setting ("healthy cities"), literacy and national health policy [8]. Approximately one and a half billion people worldwide are overweight and at least 400 million of them are obese [9]. In the PROCAM study, which examined the German population, $33 \%$ of women and $35 \%$ of men were overweight. Müller et al. [10] estimated an average body mass index (BMI) of the German population in 2040 of up to $30 \mathrm{~kg} / \mathrm{m}^{2}$.

In this study, we compared metabolic risk in two working groups that differed widely in their activities: firefighters and office workers. In their daily work, firefighters are exposed to high physical and psychological stress [1113], which is associated with high health risk [14, 15]. Therefore, good physical health is both necessary and expected as it reduces physical danger considerably. The second group comprised office workers in public administration, a numerically large workforce in Germany with approximately 18.5 million civil servants [16]. It is known that civil servants exhibit different health-risk behaviors and health forecasts according to the employment grade [17]. Working as an office worker in an administrative authority is characterized typically by sedentary work, which is associated with increased cardiovascular and metabolic risk factors $[18,19]$. Indeed, studies from other countries have shown that working in an office environment is characterized by an unhealthy lifestyle and physical inactivity [20].

To date, little is known about the impact of working conditions for development of the MetS. It is therefore of major medical and socio-economic interest to examine different occupational groups regarding their metabolic risks and to compare the results in an international context.

\section{Methods}

\section{Study population}

We examined 143 male subjects (97 firefighters and 46 office workers). The firefighters group comprised fulltime firefighters from fire departments of cities in the Westphalia area of Germany. Inclusion criteria were a full-time job as a firefighter and a regular participation in active emergency service. All firefighters worked on a shift schedule (shift duty $24 \mathrm{~h} / 2-3$ non-working days). The office worker group worked in the public administration of cities in the Westphalia area. The recruitment of study participants was performed on the basis of advertisements on workplace noticeboards and social media. Participation was voluntary.

\section{Information and informed consent}

The study was approved by the Ethics Committee of the University of Witten/Herdecke (application no. 121/2013). Each subject was informed about participation in the study and gave their written consent.

\section{Examinations}

Anthropometric parameters and medical history were collected by questionnaires. Body weight and body composition were determined using the Tanita BC-418MA Segmental Body Composition Analyzer (Tanita Corporation, Japan) [21]. A blood sample was obtained at the beginning of the examination to ascertain hematological parameters. Blood pressure measurements were performed using a calibrated standard blood pressure cuff with the subject in a supine position. Waist circumference was measured at the end of expiration while the subject was standing, using a measuring tape place around the waist at the midpoint between the lower edge of the ribs and the upper edge of the iliac crest. Diagnosis of the MetS was based on the criteria of the International Diabetes Federation (IDF) in 2005 [22].

\section{Statistical analysis}

All statistical analysis was performed using Stata/IC 13.1 for Windows (StataCorp LP, College Station, TX). Categorical characteristics were described by specifying absolute and relative frequency. Anthropometric parameters, clinical and hematological characteristics parameters were described using mean, standard deviations (SD) and medians. Differences among groups were estimated using linear regression adjusted for age because most of the analyzed parameters were directly age-related; $95 \%$ confidence intervals (CIs) are also reported. All statistical tests were two-sided with a significance level of 0.05 .

\section{Results}

Age and professional experience

Table 1 shows the age and professional experience of the examined study population. Participating firefighters had an average age of $40.5 \pm 9$ years (range 23-58) and office workers had an average age of $45.8 \pm 10$ years (range 26-62). A significant difference was found between the age of the two groups [5.30 CI (1.86-8.74); $\mathrm{p}=0.003]$. Therefore, in subsequent comparisons the results were adjusted for age. No significant difference was found for the professional experience of the two groups. On average, professional experience of firefighters was $16.3 \pm 9.1$ years (range 2.5-37) and office workers $21.1 \pm 10.8$ years (range 3-46), taking into account any training period. 
Table 1 Age and professional experience of the study population

\begin{tabular}{|c|c|c|c|c|c|c|c|c|c|}
\hline & \multicolumn{4}{|c|}{ Firefighters } & \multicolumn{4}{|c|}{ Office workers } & \multirow{2}{*}{$\begin{array}{l}\text { Office worker vs. firefighter } \\
\text { Estimated difference }{ }^{\mathrm{a}}(95 \%-\mathrm{Cl}) \\
\text { p value }\end{array}$} \\
\hline & $n$ & Mean & SD & Median & $n$ & Mean & SD & Median & \\
\hline Age (years) & 97 & 40.5 & 9.0 & 41.0 & 46 & 45.8 & 10.0 & 48.0 & $\begin{array}{l}5.30(1.86 \text { to } 8.74) \\
p=0.003\end{array}$ \\
\hline Professional experience (years) & 97 & 16.3 & 9.1 & 15.0 & 46 & 21.1 & 10.8 & 21.5 & $\begin{array}{l}0.34(-2.07 \text { to } 2.76) \\
p=0.779\end{array}$ \\
\hline
\end{tabular}

${ }^{a}$ Linear regression adjusted for age

Table 2 Anthropometric characteristics of the study population

\begin{tabular}{|c|c|c|c|c|c|c|c|c|c|}
\hline & \multicolumn{4}{|c|}{ Firefighters } & \multicolumn{4}{|c|}{ Office workers } & \multirow{2}{*}{$\begin{array}{l}\text { Office worker vs. firefighter } \\
\text { Estimated difference } \\
(95 \% \mathrm{Cl}) / \\
\text { p-value }\end{array}$} \\
\hline & $n$ & Mean & SD & Median & $n$ & Mean & SD & Median & \\
\hline Weight (kg) & 97 & 85.9 & 11.5 & 85.1 & 46 & 87.1 & 13.4 & 83.8 & $\begin{array}{l}0.13(-4.38 \text { to } 4.64) \\
p=0.955\end{array}$ \\
\hline Height (cm) & 97 & 182.2 & 6.3 & 182.0 & 46 & 181.5 & 5.4 & 182.0 & $\begin{array}{l}-0.10(-2.12 \text { to } 1.93) \\
p=0.924\end{array}$ \\
\hline BMI $\left(\mathrm{kg} / \mathrm{m}^{2}\right)$ & 97 & 25.9 & 3.2 & 25.1 & 46 & 26.4 & 4.1 & 25.5 & $\begin{array}{l}0.08(-1.22 \text { to } 1.38) \\
p=0.904\end{array}$ \\
\hline Body surface area & 97 & 2.08 & 0.16 & 2.09 & 46 & 2.09 & 0.17 & 2.05 & $\begin{array}{l}0.00(-0.06 \text { to } 0.06) \\
p=0.999\end{array}$ \\
\hline Muscle mass (kg) & 97 & 67.1 & 6.9 & 67.2 & 46 & 65.3 & 6.4 & 65.7 & $\begin{array}{l}-1.72(-4.15 \text { to } 0.70) \\
p=0.162\end{array}$ \\
\hline Body fat (\%) & 97 & 17.7 & 6.2 & 17.5 & 46 & 20.8 & 6.5 & 20.3 & $\begin{array}{l}2.05(-0.23 \text { to } 4.33) \\
p=0.078\end{array}$ \\
\hline
\end{tabular}

a Linear regression adjusted for age

\section{Anthropometric characteristics}

Table 2 describes anthropometric measurements of the two groups. No significant differences were found between the two groups in weight, height, BMI, muscle mass and body surface area. Although no significant differences were found between body fat, firefighters had a lower body fat percentage accompanied with a higher muscle mass than office workers. BMI in both groups was above the normal value of $\leq 25 \mathrm{~kg} / \mathrm{m}^{2}$ and thus corresponded to pre-obesity.

\section{Metabolic risk factors}

A significant difference was found in waist circumference, one of the central risk factors of metabolic syndrome, between firefighters and office workers [5.08 CI (1.44-8.71), $\mathrm{p}=0.007$ ]. Average abdominal waist circumferences was $89.8 \mathrm{~cm}$ in firefighters and $97.3 \mathrm{~cm}$ in office workers, which was above the threshold of $\geq 94 \mathrm{~cm}$ recommended by the IDF to define abdominal obesity. No significant differences were found for the remaining metabolic risk factors (Table 3).
Table 4 outlines the number and frequency of the presence of normal or abnormal values of risk factors of MetS according to IDF criteria. Statistically significant differences were found for the subdivision of the risk parameters in normal and abnormal waist circumference $(\mathrm{p}=0.003)$ and HDL-value $(\mathrm{p}=0.031)$, although these relationships were abolished after adjusting for age. The difference between the two groups by the factor waist circumference was clinically relevant (logistic regression adjusted for age $\mathrm{p}=0.051$ ).

In all other risk factors (triglycerides, HDL, blood pressure, blood sugar, waist circumference, BMI) the values for firefighters were more often in percentage terms of the normal range than those of the office workers (Table 4).

\section{Metabolic syndrome}

Before adjusting for age, the MetS was diagnosed significantly more often in office workers than in firefighters $(p=0.015)$. After adjusting for age, the MetS remained more common in office workers, although 
Table 3 Metabolic risk factors for diagnosis of metabolic syndrome according to the IDF

\begin{tabular}{|c|c|c|c|c|c|c|c|c|c|}
\hline & \multicolumn{4}{|c|}{ Firefighters } & \multicolumn{4}{|c|}{ Office workers } & \multirow{2}{*}{$\begin{array}{l}\text { Office worker vs. firefighter } \\
\text { Estimated difference }{ }^{\mathrm{a}}(95 \% \mathrm{Cl}) \\
\text { p value }\end{array}$} \\
\hline & $\mathbf{n}$ & Mean & SD & Median & $\mathbf{n}$ & Mean & SD & Median & \\
\hline \multicolumn{10}{|l|}{ Central risk factors } \\
\hline Waist circumference (cm) & 97 & 89.8 & 10.0 & 90.0 & 46 & 97.3 & 11.7 & 94.5 & $5.08(1.44$ to 8.71$) p=0.007$ \\
\hline BMI $\left(\mathrm{kg} / \mathrm{m}^{2}\right)$ & 97 & 25.9 & 3.2 & 25.1 & 46 & 26.4 & 4.1 & 25.5 & $0.08(-1.22$ to 1.38$) p=0.904$ \\
\hline \multicolumn{10}{|l|}{ Other risk factors } \\
\hline Triglyceride (mg/dl) & 97 & 142.2 & 75.1 & 126.0 & 46 & 162.1 & 91.4 & 130.0 & $9.55(-19.37$ to 38.47$) p=0.515$ \\
\hline $\mathrm{HDL}(\mathrm{mg} / \mathrm{dl})$ & 97 & 55.5 & 12.7 & 53.0 & 46 & 55.8 & 14.8 & 54.5 & $0.61(-4.18$ to 5.40$) p=0.802$ \\
\hline $\mathrm{RRs}_{\text {Rest }}(\mathrm{mmHg})$ & 97 & 126.4 & 9.8 & 128.0 & 46 & 129.1 & 11.7 & 130.0 & $2.19(-1.81$ to 6.19$) p=0.281$ \\
\hline $\mathrm{RR}_{\text {dRest }}(\mathrm{mmHg})$ & 97 & 84.1 & 7.4 & 80.0 & 46 & 86.6 & 8.7 & 90.0 & $1.55(-1.34$ to 4.44$) p=0.292$ \\
\hline $\mathrm{HbA1c}(\%)$ & 97 & 5.4 & 0.3 & 5.5 & 46 & 5.4 & 0.6 & 5.4 & $-0.09(-0.25$ to 0.07$) p=0.255$ \\
\hline
\end{tabular}

a Linear regression adjusted for age

Table 4 Number and frequency of the presence of normal or abnormal values of risk factors of metabolic syndrome according to the criteria of the IDF [22]

\begin{tabular}{|c|c|c|c|c|c|c|}
\hline & \multicolumn{2}{|l|}{ Firefighters } & \multicolumn{2}{|c|}{ Office workers } & \multirow[t]{2}{*}{ p value* } & \multirow[t]{2}{*}{ p value** } \\
\hline & Normal & Abnormal & Normal & Abnormal & & \\
\hline Triglyceride (mg/dl) & $62(63.9 \%)$ & $35(36.1 \%)$ & $28(60.9 \%)$ & $18(39.1 \%)$ & 0.853 & 0.664 \\
\hline $\mathrm{HDL}(\mathrm{mg} / \mathrm{dl})$ & $94(96.9 \%)$ & $3(3.1 \%)$ & $40(87.0 \%)$ & $6(13.0 \%)$ & 0.031 & 0.070 \\
\hline $\mathrm{RRs}_{\text {Rest }}(\mathrm{mmHg})$ & $49(50.5 \%)$ & $48(49.5 \%)$ & $17(37.0 \%)$ & $29(63.0 \%)$ & 0.152 & 0.195 \\
\hline $\operatorname{RRd}_{\text {Rest }}(\mathrm{mmHg})$ & $58(59.8 \%)$ & $39(40.2 \%)$ & $21(45.7 \%)$ & $25(54.3 \%)$ & 0.150 & 0.296 \\
\hline Blood glucose (mg/dl) & $94(96.9 \%)$ & $3(3.1 \%)$ & $42(91.3 \%)$ & $4(8.7 \%)$ & 0.212 & 0.613 \\
\hline Waist circumference $(\mathrm{cm})$ & $66(68.0 \%)$ & $31(32.0 \%)$ & $19(41.3 \%)$ & $27(58.7 \%)$ & 0.003 & 0.051 \\
\hline BMI $\left(\mathrm{kg} / \mathrm{m}^{2}\right)$ & 87 (89.7 \%) & 10 (10.3\%) & 40 (87.0 \%) & 6 (13.0 \%) & 0.777 & 0.831 \\
\hline
\end{tabular}

* Exact Fisher-test

** Logistic regression adjusted for age

the difference was no longer significant (odds ratio 2.1 $(0.8-5.2), p=0.122)$. The MetS was diagnosed in nearly one out of three office workers (32.6\%) according to IDF criteria, but only in $14.4 \%$ of firefighters (Table 5 ). The highest prevalence of MetS by firefighters was in the age group from 41 to 50 years $(24.3 \%$ of firefighters in this age group had a MetS), by office workers in the age group $>50$ years $(38.9 \%)$.

\section{Discussion}

Abdominal circumference was significantly higher in office workers than in firefighters and therefore the prevalence of central obesity was more apparent. Furthermore, office workers had lower HDL cholesterol levels then firefighters, which was almost significant after adjusting for age. Other relevant factors, such as triglycerides, blood pressure and blood sugar levels did not significantly differ between office workers and firefighters.
In the firefighter group, an increased waist circumference was found in $32 \%$ of the subjects, whereas for office workers this increased to more than half (58.7\%). Central obesity can be detected by waist circumference or BMI by IDF defined criteria.

Regarding BMI, both groups were slightly above the normal range of $25 \mathrm{~kg} / \mathrm{m}^{2}$, and no significant difference was found between the groups.

In this study, the definition of the International Diabetes Federation (IDF) was used to diagnose the MetS [22]; however, other definitions have been used by the World Health Organization (WHO) [23], the National Cholesterol Education Program (NCEP) [24], the American Heart Association (AHA) and the National Heart, Lung and Blood Institute (NHLBI) [25]. Overall, the prevalence of the MetS ultimately depends on the definition used. The use of the IDF definition of the MetS results in a higher prevalence of the MetS than other criteria [26]. 
Table 5 Diagnosis of metabolic syndrome (number/frequency) according to the criteria of the IDF [22]

\begin{tabular}{lllll}
\hline & $\mathbf{n}$ & No metabolic syndrome & Metabolic syndrome & p value (exact Fisher-test) \\
\hline Firefighter & 97 & $83(85.6 \%)$ & $14(14.4 \%)$ & 0.015 \\
Office worker & 46 & $31(67.4 \%)$ & $15(32.6 \%)$ & \\
Prevalence of metabolic syndrome categorized in age groups & $31-40$ & $41-50$ & $>50$ \\
Age & $\leq 30$ & $2(6.3 \%)$ & $9(24.3 \%)$ & $3(23.1 \%)$ \\
Firefighter & $0(0 \%)$ & $1(20 \%)$ & $6(35.3 \%)$ & $7(38.9 \%)$ \\
Office worker & $1(16.6 \%)$ & & & \\
\hline
\end{tabular}

The IDF definition for the MetS focuses on four criteria: obesity, dyslipidemia, hypertension and insulin resistance. For the diagnosis, the main criterion obesity and two more of the above criteria must be present.

Analyzing BMI for the diagnosis of overweight, only $10.3 \%$ of firefighters in our study were overweight. When compared with the survey by Wilkinson et al. [27], where $82.5 \%$ of all American firefighters were overweight or obese, the prevalence of overweight in German firefighters is markedly lower. High BMI values are also found in police officers, and may reflect a general problem in the public security sector [28]. However, several studies have found that waist circumference is a more precise measuring instrument for assessment of obesity than BMI [29]. Therefore, waist circumference measurement should be used for the diagnosis of obesity in firefighters [30, 31]. A similar result was found in a study by Lee et al. [32], who demonstrated that the MetS is independent of BMI. Nevertheless, BMI has a positive benefit for the assessment of general health status with firefighters because a high BMI is associated with a lower health status [33]. Similarly, the waist circumference for diagnosis of obesity in office workers seems to be more precise. By considering our examined office workers, a strong discrepancy between abnormal values of waist circumference and BMI was found (abnormal values waist circumference: $58.7 \%$, BMI: $13 \%)$.

The significantly higher abdominal circumferences in office workers are likely due to sedentary work activities. Longer sedentary activities are associated with higher abdominal circumferences and the severity of a metabolic risk [34]. Long sedentary work is also linked with lower HDL cholesterol levels [18], and is consistent with our findings.

Using the IDF criteria, MetS was detected in $14.4 \%$ of investigated firefighters and in $32.6 \%$ of office workers. The prevalence of the MetS in firefighters in our study strongly correlates with the results of Donovan et al. [35], who reported that $15 \%$ of American firefighters were diagnosed with MetS. However, two other studies from American firefighters showed a higher prevalence of the
MetS [36, 37]. The question arises whether it is possible to transfer the findings of firefighters from other nations to the local conditions. It can be assumed that differences in professional activities and nutrition exist. It would be important to compare our study with other studies on German firefighters; however an extensive literature search yielded no results on other national studies, which points to neglect of the firefighting profession and this subject in Germany.

A literature review yielded no results on studies of the MetS in German office workers. In the general German population, a MetS prevalence of $32.7 \%$ is described using the IDF definition [38]. The prevalence of MetS in the United States population is similar [39]. From 2003 to 2012, the overall prevalence of the MetS in the United States was $33 \%$ (95 \% CI $32.5 \% 33.5 \%$ ) [39]. Our office workers represent a cohort of professionals with mainly sedentary work activity. Almost one third of all office workers presented an existing MetS. Other studies have already concluded that office working is characterized by an unhealthy lifestyle $[19,20]$. Our office worker group displayed a higher health hazard, shown in a higher prevalence of MetS, similar to investigated office workers of Bangkok [40]. The effects of metabolic risk factors and their importance have been studied for many years, but it tends to be clinically under recognized [41]. In the future, the incidence of the MetS will continue to increase. To determine the impact of occupation on these factors, further studies (in Germany) are needed. Studies in other countries have already indicated that in some cases there are important differences in the prevalence of the MetS itself and between different occupational groups [39]. Table 6 shows a comparison of the prevalence of the MetS in our group with other professional groups in different countries.

A change in life-style practices is required to reduce metabolic risk. Impaired sleep rhythm is a factor which in turn is a risk factor for metabolic syndrome. Especially the eating behaviour is changed and interacts healthy nutrition and development of weight [42]. Night work causes a mismatch between the endogenous circadian 
Table 6 Prevalence of metabolic syndrome in published studies of firefighters and office workers

\begin{tabular}{|c|c|c|c|c|c|c|c|}
\hline \multicolumn{8}{|c|}{ Prevalence of metabolic syndrome } \\
\hline \multicolumn{4}{|l|}{ Firefighters } & \multicolumn{4}{|l|}{ Office workers } \\
\hline Study & Prevalence (\%) & Country & Criteria & Study & Prevalence (\%) & Country & Criteria \\
\hline Own results & 14.4 & Germany & IDF & Own results & 32.6 & Germany & IDF \\
\hline Title et al. [58] & 19 & Canada & Modified NCEP/ATP III & $\begin{array}{l}\text { Lohsoonthorn et al. } \\
\text { [40] }\end{array}$ & 25.8 & Thailand & Modified NCEP/ATP III \\
\hline Carey et al. [37] & 46.7 & USA & $\begin{array}{l}\text { National Institutes of } \\
\text { Health Criteria } 4\end{array}$ & Konradi et al. [20] & 34.6 & Russia & IDF \\
\hline Donovan et al. [35] & 15 & USA & ModifiedNCEP/ATP III & Suh et al. [59] & 7.4 & Korea & Modified NCEP/ATP III \\
\hline Baur et al. [36] & 28.3 & USA & $\begin{array}{l}\text { Modified criteria of } \\
\text { joint scientific } \\
\text { statements [25] }\end{array}$ & Matsuura et al. [60] & 16 & Japan & Japanese criteria [61] \\
\hline
\end{tabular}

timing system and the environmental synchronizers (light/dark cycle) $[43,44]$. The Career Firefighters participated in this study work $24 \mathrm{~h}$ and have 3 non-working days. After that they work again $24 \mathrm{~h}$ a have again 3 non-working days. It might by presumed, that this shift work can change the nutrition habits and assisted to the development of metabolic syndrome [45-47]. It is well known that physical activity has a positive effect on metabolic risk factors [48-50]. Regarding the fire service, it has been proven that obese firefighters have a poorer health status and are more vulnerable to weight gain [51]. In addition, study results of American firefighters show significantly better cardiorespiratory fitness and less metabolic risk factors in normal weight versus overweight firefighters [52]. The enormous importance of cardiorespiratory fitness in relation to the metabolic system is demonstrated in a study of Baur et al. [36], who showed that the MetS was inversely proportional to cardiorespiratory fitness. These results underscore the importance of an approach for reducing the prevalence of the MetS in firefighters. It known that an increase in cardiorespiratory fitness is associated with a reduction in metabolic risk factors in firefighters [35]. Also, cardiorespiratory fitness is a necessary vital factor for admission to the firefighter service. Indeed, good cardiorespiratory fitness is a fundamental starting point for the promotion and maintenance of health in firefighters. Therefore, firefighters should try to improve their cardiorespiratory fitness through targeted training, thereby simultaneously minimizing metabolic risk factors. Examined office workers show a higher prevalence of MetS than those of the general German population. Office workers therefore seem to be particularly at risk for the development of MetS. It is absolutely necessary to reduce this risk with preventative measures. The first approach should be a change of lifestyle. This could be realized by increased physical activity and a change in diet. It has been shown that office workers do not compensate their sedentary lifestyles with physical activity during their leisure time [50, 53]. An investigation by Maruyama et al. [54] in 2010 showed a positive effect of physical activity with simultaneous participation in a nutrition program in "white collar workers" in relation to a reduction in body weight, BMI and fasting glucose levels.

\section{Conclusions}

In conclusion, our results demonstrate that firefighters have lower metabolic risk than office workers. Shift work and stressful job conditions in professional firefighters might be more likely associated with increased cardiovascular risks $[55,56]$. But, we cannot exclude the possibility that firefighters enjoy a healthier lifestyle. Firefighters presented less frequent abnormal values of all considered criteria for diagnosis of the MetS. Office workers had a significantly greater abdominal waist circumference than firefighters. Thus, it does not seem surprising that in our study the rate of the MetS was higher for office workers than firefighters. Previous research has also described a difference of metabolic risk between different occupational groups and there is mounting evidence that a link between the metabolic risk and the occupation exists. Occupational groups need to be made aware of the risk and health promoting concepts have to be implemented in daily lives, such as corporate sports activities or nutrition education. Further studies are required to determine the occupational impact on health different local conditions.

\section{Limitation}

The ratio of waist to hip circumference ratio would provide a further information about the metabolic syndrome and cardiovascular risks in firefighters and office workers [57]. In the present study we did not measure this factor. For future scientific work this ration has to be considered. 


\section{Abbreviations}

BMI: body mass index; HDL: high-density-lipoprotein; IDF: International Diabetes Federation; MetS: metabolic syndrome.

\section{Authors' contributions}

Study conception and design: MS, PF, RL. Data acquisition: MS, PF, RL. Data analysis and interpretation: MS, PF, RL, FSG, AL Statistical analysis: MS, RL. Drafting the manuscript: MS. Critical revision of the manuscript for important intellectual content: MS, PF, BP, MH, RL, FSG, AL. Final approval of the version to be published: $M S, P F, B P, M H, R L, F S G, A L$ Obtained funding: RL. Administrative, technical, or material support: MS, PF, RL. All authors read and approved the final manuscript.

\section{Author details}

${ }^{1}$ Department of Cardiology, Sector preventive medicine, health promotion, Faculty of Health, School of Medicine, University Witten/Herdecke, Elberfelderstr. 1, 58095 Hagen, Germany. ${ }^{2}$ Department of Cardiology, Faculty of Health, School of Medicine, University Witten/Herdecke, Urbacher Weg 19, 51149 Cologne, Germany. ${ }^{3}$ Research Institute of the Hospital 12 de Octubre $\left(" \mathrm{i}+12^{\prime \prime}\right)$, Madrid, Spain. ${ }^{4}$ European University of Madrid, Madrid, Spain.

\section{Acknowledgements}

We thank Hiltrud Niggemann for the support by statistical analysis.

\section{Competing interests}

The authors declare that they have no competing interests.

\section{Funding acknowledgment statement}

This research received no specific grant from any funding agency in the public, commercial, or not-for-profit sectors.

Received: 27 April 2016 Accepted: 1 August 2016

Published online: 22 August 2016

\section{References}

1. Ford ES, Giles WH, Mokdad AH. Increasing prevalence of the metabolic syndrome among US Adults. Diab Care. 2004;27:2444-9.

2. Neuhauser H, Ellert U. Prävalenz des metabolischen Syndroms in Deutschland: eine Sensitivitätsanalyse. In: Meeting abstract science ggm ed. 2005. http://www.egms.de/en/meetings/gmds2005/05gmds183. shtml. Accessed 15 Mar 2016.

3. Prävention Assmann Stiftung. Anteil der am metabolischen Syndrom Erkrankten in verschiedenen Altersstufen der Procam Studie. 2014. http:// www.assmann-stiftung.de/praevention/herzinfarkt/metabolischessyndrom/. Accessed 14 Nov 2014

4. Bonora E, Kiechl S, Willeit J, Oberhollenzer F, Egger G, Bonadonna RC, Muggeo M. Carotid atherosclerosis and coronary heart disease in the metabolic syndrome: prospective data from the Bruneck study. Diab Care. 2003;26:1251-7.

5. Isomaa B, Almgren P, Tuomi T, Forsen B, Lahti K, Nissen M, Taskinen MR, Groop L. Cardiovascular morbidity and mortality associated with the metabolic syndrome. Diab Care. 2001;24:683-9.

6. Lakka HM, Laaksonen DE, Lakka TA, Niskanen LK, Kumpusalo E, Tuomilehto J, Salonen JT. The metabolic syndrome and total and cardiovascular disease mortality in middle-aged men. JAMA. 2002;288:2709-16.

7. King H, Aubert RE, Herman WH. Global burden of diabetes, 19952025: prevalence, numerical estimates, and projections. Diab Care. 1998:21:1414-31.

8. Leischik R, Dworrak B, Strauss M, Przybylek B, Dworrak T, Schöne D, Horlitz M, Mügge A. Plasticity of health. Ger J Med. 2016;1:1-17.

9. WHO. Obesity: preventing and managing the global epidemic Report of a WHO consultation. World Health Organ Tech Rep Ser. 2000:894(1-12):1-253.

10. Müller M, Reinehr T, Hebebrand J. Prävention und Therapie von Übergewicht im Kindes- und Jugendalter. Deutsches Ärzteblatt. 2006;103:334-40
11. Williford HN, Duey WJ, Olson MS, Howard R, Wang N. Relationship between fire fighting suppression tasks and physical fitness. Ergonomics. 1999:42:1179-86.

12. Barnard RJ, Gardner GW, Diaco NV. "Ischemic" heart disease in fire fighters with normal coronary arteries. J Occup Med. 1976:18:818-20.

13. Drew-Nord DC, Hong O, Froelicher ES. Cardiovascular risk factors among career firefighters. Aaohn J. 2009;57:415-22 (quiz 423).

14. Kales SN, Soteriades ES, Christophi CA, Christiani DC. Emergency duties and deaths from heart disease among firefighters in the United States. N Engl J Med. 2007;356:1207-15

15. Strauß M, Karutz H, Foshag P, Spelsberg N, Dworrak B, Horlitz M, Leischik R. Fit for rescue? Notfall + Rettungsmedizin. 2016;19:364-72.

16. Berufsforschung IFA. Berufe im Spiegel der Statistik. 2011. http://bisds. infosys.iab.de/bisds/result?beruf=BO781. Accessed 15 Nov 2014.

17. Marmot MG, Smith GD, Stansfeld S, Patel C, North F, Head J, White I, Brunner E, Feeney A. Health inequalities among British civil servants: the Whitehall II study. Lancet. 1991;337:1387-93.

18. Healy GN, Matthews CE, Dunstan DW, Winkler EA, Owen N. Sedentary time and cardio-metabolic biomarkers in US adults: NHANES 2003-06. Eur Heart J. 2011:32:590-7.

19. Edwardson CL, Gorely T, Davies MJ, Gray LJ, Khunti K, Wilmot EG, Yates T, Biddle SJ. Association of sedentary behaviour with metabolic syndrome: a meta-analysis. PLoS One. 2012;7:e34916.

20. Konradi AO, Rotar OP, Korostovtseva LS, Ivanenko VV, Solntcev VN, Anokhin SB, Bart VA, Shlyakhto EV. Prevalence of metabolic syndrome components in a population of bank employees from St. Petersburg, Russia. Metab Syndr Relat Disord. 2011;9:337-43.

21. Ackland TR, Lohman TG, Sundgot-Borgen J, Maughan RJ, Meyer NL, Stewart AD, Muller W. Current status of body composition assessment in sport: review and position statement on behalf of the ad hoc research working group on body composition health and performance, under the auspices of the I.O.C. Medical Commission. Sports Med. 2012;42:227-49.

22. Alberti KG, Zimmet P, Shaw J. The metabolic syndrome-a new worldwide definition. Lancet. 2005;366:1059-62

23. Alberti KG, Zimmet PZ. Definition, diagnosis and classification of diabetes mellitus and its complications. Part 1: diagnosis and classification of diabetes mellitus provisional report of a WHO consultation. Diab Med. 1998:15:539-53.

24. National Cholesterol Education Program (NCEP) Expert. Executive summary of The third report of The National Cholesterol Education Program (NCEP) Expert panel on detection, evaluation, and treatment of high blood cholesterol in adults (adult treatment panel III). JAMA 2001;285:2486-97.

25. Alberti KG, Eckel RH, Grundy SM, Zimmet PZ, Cleeman Iال Donato KA, Fruchart JC, James WP, Loria CM, Smith SC Jr. Harmonizing the metabolic syndrome: a joint interim statement of the international diabetes federation task force on epidemiology and prevention; national heart, lung, and blood institute; American heart association; world heart federation; international atherosclerosis society; and international association for the study of obesity. Circulation. 2009;120:1640-5.

26. Ford ES. Prevalence of the metabolic syndrome defined by the International Diabetes Federation among adults in the US. Diab Care. 2005:28:2745-9.

27. Wilkinson ML, Brown AL, Poston WS, Haddock CK, Jahnke SA, Day RS. Physician weight recommendations for overweight and obese firefighters, United States, 2011-2012. Prev Chronic Dis. 2014;11:E116.

28. Thayyil J, Jayakrishnan TT, Raja M, Cherumanalil JM. Metabolic syndrome and other cardiovascular risk factors among police officers. N Am J Med Sci. 2012;4:630-5.

29. Janssen I, Katzmarzyk PT, Ross R. Waist circumference and not body mass index explains obesity-related health risk. Am J Clin Nutr. 2004:79:379-84.

30. Jitnarin N, Poston WS, Haddock CK, Jahnke S, Tuley BC. Accuracy of body mass index-defined overweight in fire fighters. Occup Med (Lond). 2013:63:227-30.

31. Ode J, Knous J, Schlaff R, Hemenway J, Peterson J, Lowry J. Accuracy of body mass index in volunteer firefighters. Occup Med (Lond). 2014;64:193-7

32. Lee WJ, Huang MT, Wang W, Lin CM, Chen TC, Lai IR. Effects of obesity surgery on the metabolic syndrome. Arch Surg. 2004;139:1088-92. 
33. Clark S, Rene A, Theurer WM, Marshall M. Association of body mass index and health status in firefighters. J Occup Environ Med. 2002:44:940-6.

34. Healy GN, Wijndaele K, Dunstan DW, Shaw JE, Salmon J, Zimmet PZ, Owen N. Objectively measured sedentary time, physical activity, and metabolic risk: the Australian diabetes, obesity and lifestyle study (AusDiab). Diab Care. 2008;31:369-71.

35. Donovan R, Nelson T, Peel J, Lipsey T, Voyles W, Israel RG. Cardiorespiratory fitness and the metabolic syndrome in firefighters. Occup Med (Lond) 2009;59:487-92.

36. Baur DM, Christophi CA, Kales SN. Metabolic syndrome is inversely related to cardiorespiratory fitness in male career firefighters. J Strength Cond Res. 2012;26:2331-7.

37. Carey MG, Al-Zaiti SS, Liao LM, Martin HN, Butler RA. A low-glycemic nutritional fitness program to reverse metabolic syndrome in professional firefighters: results of a pilot study. J Cardiovasc Nurs. 2011;26:298-304.

38. Moebus S, Hanisch JU, Aidelsburger P, Bramlage P, Wasem J, Jockel KH. Impact of 4 different definitions used for the assessment of the prevalence of the metabolic syndrome in primary healthcare: the german metabolic and cardiovascular risk project (GEMCAS). Cardiovasc Diabetol. 2007;6:22.

39. Aguilar M, Bhuket T, Torres S, Liu B, Wong RJ. Prevalence of the metabolic syndrome in the United States, 2003-2012. JAMA. 2015:313:1973-4.

40. Lohsoonthorn V, Lertmaharit S, Williams MA. Prevalence of metabolic syndrome among professional and office workers in Bangkok, Thailand. J Med Assoc Thai. 2007;90:1908-15.

41. Sperling LS, Mechanick JI, Neeland IJ, Herrick CJ, Despres JP, Ndumele CE, Vijayaraghavan K, Handelsman Y, Puckrein GA, Araneta MR, et al. The cardiometabolic health alliance: working toward a new care model for the metabolic syndrome. J Am Coll Cardiol. 2015;66:1050-67.

42. Lowden A, Moreno C, Holmbäck U, Lennernäs M, Tucker P. Eating and shift work-effects on habits, metabolism and performance. Scand J Work Environ Health. 2010;36:150-62.

43. Costa G. Shift work and occupational medicine: an overview. Occup Med (Lond). 2003;53:83-8.

44. Folkard S, Minors DS, Waterhouse JM. Chronobiology and shift work: current issues and trends. Chronobiologia. 1985;12:31-54.

45. Lin YC, Hsieh IC, Chen PC. Utilizing the metabolic syndrome component count in workers' health surveillance: an example of day-time vs. day-night rotating shift workers. Int J Occup Med Environ Health. 2015:28:675-88

46. Mashhadi NS, Saadat S, Afsharmanesh MR, Shirali S. Study of association between beverage consumption pattern and lipid profile in shift workers. Diab Metab Syndr. 2016. doi:10.1016/j.dsx.2016.06.011.

47. Nea FM, Kearney J, Livingstone MB, Pourshahidi LK, Corish CA. Dietary and lifestyle habits and the associated health risks in shift workers. Nutr Res Rev. 2015;28:143-66.

48. Cooper AJ, Brage S, Ekelund U, Wareham NJ, Griffin SJ, Simmons RK. Association between objectively assessed sedentary time and physical activity with metabolic risk factors among people with recently diagnosed type 2 diabetes. Diabetologia. 2014;57:73-82.
49. Simmons RK, Griffin SJ, Steele R, Wareham NJ, Ekelund U. Increasing overall physical activity and aerobic fitness is associated with improvements in metabolic risk: cohort analysis of the ProActive trial. Diabetologia. 2008;51:787-94.

50. Arem H, Moore SC, Patel A, Hartge P, de Gonzalez AB, Visvanathan K, Campbell PT, Freedman M, Weiderpass E, Adami HO, et al. Leisure time physical activity and mortality: a detailed pooled analysis of the doseresponse relationship. JAMA Intern Med. 2015;175:959-67.

51. Soteriades ES, Hauser R, Kawachi I, Liarokapis D, Christiani DC, Kales SN. Obesity and cardiovascular disease risk factors in firefighters: a prospective cohort study. Obes Res. 2005;13:1756-63.

52. Baur DM, Christophi CA, Tsismenakis AJ, Jahnke SA, Kales SN. Weightperception in male career firefighters and its association with cardiovascular risk factors. BMC Publ Health. 2012;12:480.

53. Dutta N, Koepp GA, Stovitz SD, Levine JA, Pereira MA. Using sit-stand workstations to decrease sedentary time in office workers: a randomized crossover trial. Int J Environ Res Publ Health. 2014;11:6653-65.

54. Maruyama C, Kimura M, Okumura H, Hayashi K, Arao T. Effect of a worksite-based intervention program on metabolic parameters in middleaged male white-collar workers: a randomized controlled trial. Prev Med. 2010;51:11-7

55. Bannai A, Tamakoshi A. The association between long working hours and health: a systematic review of epidemiological evidence. Scand J Work Environ Health. 2014;40:5-18.

56. Marinaccio A, Ferrante P, Corfiati M, Di Tecco C, Rondinone B, Bonafede M, Ronchetti M, Persechino B, lavicoli S. The relevance of socio-demographic and occupational variables for the assessment of work-related stress risk. BMC Publ Health. 2013;13:1157.

57. De Koning L, Merchant AT, Pogue J, Anand SS. Waist circumference and waist-to-hip ratio as predictors of cardiovascular events: meta-regression analysis of prospective studies. Eur Heart J. 2007;28:850-6.

58. Title LM, Lonn E, Charbonneau F, Fung M, Mather KJ, Verma S, Anderson TJ. Relationship between brachial artery flow-mediated dilatation, hyperemic shear stress, and the metabolic syndrome. Vasc Med. 2008;13:263-70.

59. Suh BS. The association between serum gamma-glutamyltransferase within normal levels and metabolic syndrome in office workers: a 4-year follow-up study. Korean J Fam Med. 2012;33:51-8.

60. Matsuura H, Mure K, Nishio N, Kitano N, Nagai N, Takeshita T. Relationship between coffee consumption and prevalence of metabolic syndrome among Japanese civil servants. J Epidemiol. 2012;22:160-6.

61. Committee to Evaluate Diagnostic Standards for Metabolic Syndrome. Definition and the diagnostic standard for metabolic syndrome-committee to evaluate diagnostic standards for metabolic syndrome. Nippon Naika Gakkai Zasshi. 2005;94:794-809.

\section{Submit your next manuscript to BioMed Central and we will help you at every step:}

- We accept pre-submission inquiries

- Our selector tool helps you to find the most relevant journal

- We provide round the clock customer support

- Convenient online submission

- Thorough peer review

- Inclusion in PubMed and all major indexing services

- Maximum visibility for your research

Submit your manuscript at www.biomedcentral.com/submit 